\title{
En busca de Silva
}

T OSÉ Asunción Silva, tanto el hombre como el poeta, ha sido el objeto de mucha crítica; ya existe una bibliografía silviana bastante amplia. ${ }^{1}$ Mas el caso del poeta colombiano, muerto antes de la madurez, de tanta promesa que tal vez habría llegado a fruición, no está agotado todavía, a pesar de las observaciones justas y perspicaces que se han hecho a propósito de su obra. A pesar de los estudios ya hechos, que no pretenden ser completos y que señalan con buen juicio crítico muchos puntos esenciales, nos parece que la crítica no se ha fijado bastante en la poesía de Silva qua poesía, en su léxico, en sus formas sintácticas, en la evolución de su sensibilidad manifestada en el lenguaje poético. El poeta colombiano, como todo artista, se revela más íntima y completamente en el estilo, y es allí donde hay que buscarle. A base de una especie de correlación entre el sentimiento y la palabra que le da forma, el ensayo que sigue es un esfuerzo por comprender a Silva como una sensibilidad única, quien, a la vez, com. parte con sus contemporáneos un fondo de ideas. Este estudio toma como su punto de partida la expresión concreta, y considera esta expresión una cosa orgánica y vital, que se dilata y se contrae según el pulso emocional del poeta.

Vamos a fijarnos, sobre todo, en las formas verbales que emplea el poeta, y en su uso simbólico de la sombra, como indicaciones precisas de su : percepción del mundo, y vamos a ver cómo esta percepción, hecha concreta en el lenguaje poético, hace de él un pos-romántico y modernista.

La poesía de José Așunción Silva emerge de las sombras y a ellas vuelve. En busca de la luz y de la clatidad, sus poemas surgen de esas brumas

1 Para una bibliografía completa hasta 1942, véase la edición de GarciaPrada, Prosas y versos de Silva, (México: Editorial Cultura, 1942). 
omnipresentes, se iluminan unos momentos a la luz de la luna, y con la mengua de esta luz pálida reflejada, van desapareciendo. Como los sueños de medianoche que se desvanecen en seguida, sus poemas brotan de la oscuridad, se dan a la luz unos momentos, y vuelven en fin a la sombra, como si fueran atraídos por una fuerza inexorable. "Se fueron acercando en lentas procesiones", ${ }_{2}^{2}$ dice Silva de sus sueños, y después de un solo momento de vigencia, de vida luminosa, "fueron deshaciéndose y hundiéndose en la sombra". He aquí el sentimiento silviano del universo: el mundo es dinámico, todo está en proceso de hacerse y de deshacerse, nada perdura en una forma fija. La ley de las cosas y del hombre es el cambio, la evolución.

Augusto Cortina Aravena tiene razón cuando señala la antítesis como el carácter fundamental de la poesía de Silva, ${ }^{3}$ una antítesis que se basa en este sentido dinámico del mundo y que luego se convierte en una obsesión metafísica. Pero más bien que la "antítesis", que sugiere un abismo infranqueable entre dos polos opuestos, nosotros diríamos que este carácter fundamental consiste en un hondo sentido del doble filo de toda la experiencia humana y de todos los fenómenos del mundo. Es decir, las cosas, los hombres, las sensaciones -en una palabra, TODo- están en proceso de deshacerse. Es el sentimiento agudo de la inminencia de la muerte, pero una muerte que se identifica con el proceso de la vida, una muerte que rodea la vida, como la sombra rodea la creación poética de Silva.

Parece que todo se mueve imperceptible pero inexorablemente, a lo largo de una especie de continuum, hacia la disolución, hacia el no-ser, hacia la muerte. Aquí no podemos menos que pensar en las teorias de la evolución que estaban en boga en la segunda mitad del siglo diecinueve, y que eran, tal vez, una causa inmediata del segundo romanticismo finisecular que llamamos el simbolismo y el modernismo. Silva se interesaba mucho en estas teorías, como en toda la vida intelectual de su tiempo, y ellas dejaron una huella perdurable en su sentimiento del mundo. Estas ideas cosmológicas que proponían la evolución como la ley del universo despertaron en él la imaginación viva del poeta.

The immense spectacle of human knowledge, of modern science, of sepecula tive thought, burst upon him, and for him as for how many, Herbert Spencer's First Principles was like the draught of Lucretius. As they overpassed

2 "Midnight Dreams", Poesías completas, (Madrid: Aguilar, 1951), pág. 88. De aquí en adelante, los versos citados de Silva aparecerán en el texto seguidos por el título del poema y la página en que se encuentran en esta edición de Aguilar.

3 Humanidades, X, págs. 439-451. 
the flaming ramparts of the world, as they watched the atoms dropping through the void and saw the stars whirling through infinitude, as they felt the enormous cosmical process knit up into worlds and dissolve again through recurrent eternities, the burning concepts scorched the brain. ${ }^{4}$

Como Lucrecio, poeta de ideas físico-biológicas, Silva poetiza un cosmos dinámico; pero Silva se diferencia del poeta latino en el hecho de que encuentra en el mundo objetivo, en los procesos cósmicos, un reflejo de sus procesos interiores. Es siempre el poeta lírico que se ocupa de su estado de ánimo. Como dice Alfredo Roggiano en su excelente estudio sobre Silva: "El pocta se crea en las cosas... Se transmigra constantemente a las cosas para hallar allí asidero a las formas superiores de su espíritu..."

\author{
Como Naturaleza, \\ Cuna y sepulcro eterno de las cosas, \\ El alma humana tiene ocultas fuerzas, \\ Silencios, luces, músicas y sombras...
}

("Resurrecciones", pág. 78)

Los procesos del alma humana corresponden a los de la naturaleza; las mismas leyes rigen la existencia del mundo y la vida del hombre. En los versos de Silva citados arriba, hay que notar sobre todo el último verso: "Silencios, luces, músicas y sombras", un verso sumamente silviano por la mención y la disposición de sus elementos. Los cuatro nombres arreglados así son la clave de todo su arte, de todo su sentimiento. "Silencios" y "sombras" marcan los límites del verso, son la primera palabra y la última, son una especie de molde en que el poeta ha vertido las luces y las músicas (los elementos básicos de su poesía). Pero son luces que se disolverán en la sombra, músicas que recaerán al silencio. Los símbolos del no-ser, del no-creado-las sombras, los silencios-están allí como una indicación del destino ineludible de la muerte, pero un destino que es inminente aun en los momentos de vigencia, en la luz y en la música mismas. Aquí la vida y la muerte no están vistas como dos cosas distintas y mutuamente excluyentes; al contrario, son dos partes de la misma cosa, son dos puntos sucesivos en el continuum de la existencia, el continuum a lo largo del cual todas las cosas, todos los hombres, con sus sentimientos, sus ideas, sus aspiraciones y creaciones, se mueven hacia la nada, hacia la muerte.

* Georgiana Goddard King, A Citizen of the Twilight, (New York: Longmans Green and Company, 1921), p. 9.

${ }_{5}$ José Asunción Silva, Cuadernos bispanoamericanos (Madrid, Núm. 9, mayojunio, 1949), págs. 605, 603. 


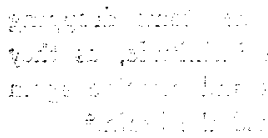

Sobre una eterna esencia

Pasos inestables de caduicas formas

$Y$ senos ignotados

Do la vida y la muerte se eslabonan.

("Resurrecciones")

Silva ve este continum de la vida y la muerte como una cadena cuyos eslabones son, en efecto, los momentos sucesivos de la existencia. Ve su propia alma como un proceso de "pasos inestables". que se forman y se deshacen sobre la "eterna esencia" de la mutabilidad, del dinamismo total, que rige el universo y el alma del hombre.

Podemos decir que la orientación total de Silva se cimenta en este principio del dinamismo cósmico, del cual la historia sentimental humana forma parte, y veremos en seguida cómo esta orientación encuentra su expresión en el verbo silviano. El gerundio y el imperfecto, sobre todo, llegan a ser las formas verbales predilectas de Silva, y las emplea con muchisima frecuencia, sobre todo cuando quiere crear un efecto del proceso de devenir de una cosa. Estas formas verbales, o formas cuyo efecto es parecido, se combinan con el símbolo de la sombra y la bruma, para crear una poesía que expresa, así en su forma como en su contenido, el sentimiento agudo del paso del tiempo y el movimiento en el tiempo de cada cosa hacia la muerte. ${ }^{6}$

Silva dice de sus sueños a medianoche: "Se fueron acercando en lentas procesiones". El poeta los percibe en su lento acercamiento hacia él, y, luego, en su alejamiento; los recuerda y los evoca en movimiento:

Los sueños se acercaron y me vieron dormido,

Se fueron alejando, sin hacerme ruido

Y sin pisar los hilos sedosos de la alfombra

$Y$ se fueron deshaciéndose $y$ hundiéndose en

la sombra! ("Midnight Dreams", pág. 78)

En estos versos, que no podrían ser sino de Silva, se identifican la forma y el contenido. Los gerundios en su forma misma nos comunican el dinamismo de los sueños, y los verbos encierran en su significación - "desha-

- Nos parece interesante que la poesía de descomposición de Neruda encuentre los mismos medios expresivos que esta poesía dinámica de Silva. Versos como "El río que durando se destruye" de Neruda y "Fueron deshaciéndose y hundiéndose en la sombra" de Silva emplean el mismo medio expresivo del geründio. Del verso de Neruda, Amado Alonso ha dicho: "...verso espléndido donde se encierra la imagen definitiva de esta dolorosa visión de la realidad". Poesía y estilo de Pablo Neruda, (Buenos Aires, 1915) pág. 19. 
ciéndose", "hundiéndose"- la descomposición y la muerte. Pero además, los gerundios son reflexivos. Así el movimiento parece volver sobre sí y. retornar a su punto de origen: los sueños vuelven a la misma sombra de donde venían surgiendo unos momentos antes, la sombra que es la última palabra del poema, y el último destino de todas las cosas.

De la misma manera que Silva parece buscar esas formas del verbo que sugieren el proceso del devenir que sufre cada cosa, el poeta co: lombiano prefiere esa hora del día en que reina la incertitud iluminativa del crepúsculo, esa hora cuando no es ni noche ni día, ni encendido por el sol ni iluminado por la luna, esa hora que es una especie de nexo movible entre dos partes de un mismo día y que siempre están en proceso de deshacerse. Es la hora azul de la fantasía pueril y de la imaginación poética, una fantasía y una imaginación que tienden a identificarse para Silva. En un poema que se titula justamente "Crepúsculo", Silva dice:

\author{
Junto de la cuna aún no está encendida \\ La lámpara tibia, que alegra y reposa \\ $Y$ se filtra opaca, por entre cortinas \\ De la tarde triste la luz azulosa. \\ Los niños, cansados, suspenden sus juegos, \\ De la calle vienen extraños ruidos, \\ En estos momentos, en todos los cuartos, \\ Se van despertando los duendes dormidos. (pág. 45).
}

Para Silva, la niñez es siempre un motivo poético, y la evoca como la edad en que se aprehende mejor la continuidad móvil de la historia del universo y de la civilización. Para él, los cuentos fantásticos pueriles son una especie de eternidad dinámica porque remontan a tiempos ignotos en la historia del hombre y porque son, y seguirán siendo, repetidos por las generaciones futuras.

Cuentos que nacisteis en ignotos tiempos,

$Y$ que vais volando, por entre lo oscuro,

Desde los potentes Aryas primitivos,

Hasta las enclenques razas del futuro.

Como la hora del crepúsculo representa la transición entre las dos partes del día que siempre están en proceso de deshacerse y de rehacerse de nuevo, el cuento infantil es un nexo entre las dos edades dinámicas del hombre: es una supervivencia eterna de un pasado que se extiende en el futuro.

Aquí, como en "Midnight Dreams", las formas verbales comunican el sentido dinámico de las cosas. Para presentar la vuelta de la hora mágica 
del crepúsculo, la hora de los duendes y las hadas, la hora fluida entre el día y la noche, Silva emplea el gerundio reflexivo en un verso íntimamente suyo por su inflexión verbal: "Se van despertando los duendes dormidos", un verso que se adelanta brincando, leve como el paso mismo de los duendes. $Y$ hablando de los cuentos infantiles que han sobrevivido desde los tiempos pre-históricos por el hecho propio de haber sido repetidos por cada generación a través de la lentitud de los siglos, Silva dice: "Cuentos... / . . que vais volando, por entre lo oscuro"; otra vez el uso del gerundio combinado con el elemento simbólico de la oscuridad - una composición sumamente silviana.

Mas el gerundio no era el único medio expresivo para Silva; sabía usar los verbos en sus demás formas para conseguir efectos parecidos al efecto del gerundio. Para crear el ambiente fluido del crepúsculo, cuando la luz del día está en proceso de disolverse en la sombra de la noche, dice:

Con atento oído las niñas la escuchan,

Las muñecas duermen, en la blanda alfombra

Medio abandonado, y en el aposento

La luz disminuye, se aumenta la sombra.

Queremos llamar la atención sobre este último verso, donde la disposición de los verbos produce el mismo efecto de movimiento y fluidez que el gerundio. Este uso de dos verbos sucesivos cuya acción se confunde en un solo hilo de movimiento era otro medio expresivo predilecto de Silva, y aparece en otros poemas suyos.

En el primer "Nocturno", que es una especie de fantaseo del poeta a partir de una melodía tocada en el piano una noche de luna, Silva dice:

A veces, cuando en alta noche tranquila, Sobre las teclas vuela tu matio blanca, Como una mariposa sobre una lila $\mathrm{Y}$ al teclado sonoro notas arranca, Cruzando del espacio la negra sombra Filtran por la ventana rayos de luna, Que trazan luces largas sobre la alfombra, $Y$ en alas de las notas a otros lugares, Vuelan mis pensamientos, cruzan los mares $Y$ en gótico castillo donde en las piedras Musgosas por los siglos, crecen las yedras. Puestos de codos ambos en tu ventana Miramos en las sombras moriv el dia 
$Y$ subir de los valles la noche umbria
Y soy tu paje rubio, mi castellana,
Y cuando en los espacios la noche cierra,
El fuego de tu estancia los muebles dora...

("A veces cuando en alta noche", pảg. 65)

Aquí tenemos los mismos recursos estilísticos que acabamos de examinar en "Midnight Dreams" y en "Crepúsculo"; el uso del gerundio combinado con el símbolo de la sombra ("Cruzando del espacio la negra sombra") y la disposición de dos verbos sucesivos (véase los versos en itálicas) cuya acción se confunde para producir el efecto dinámico del día en disolución. La hora del sueño es otra vez el crepúsculo, la hora predilecta de Silva.

Es evidente que forma y contenido van estrechamente ligados en la poesía de Silva. A base de su hondo y agudo sentimiento dinámico del mundo, va creando una poesía móvil y fluida, una poesía que encierra en sus propias formas lingüísticas el devenir del cosmos y del alma humana.

Pero al lado de esta poesía del crepúsculo y de la sombra, hay otra poesía silviana - luminosa, diáfana - una poesía de luz y de blancura.

¡Si os encerrara yo en mis estrofas

Frágiles cosas que sonreís

Pálido lirio que te deshojas

Rayo de luna sobre el tapiz

De húmedas flores, y verdes hojas

Que al tibio soplo de Mayo abrís,

$\mathrm{Si}$ os encerrara yo en mis estrofas,

Pálidas cosas que sonreís!

("La voz de las cosas", pág. 73)

Es de notar aquí, sin embargo, que a pesar de su luminosidad, esta poesía es también móvil y dinámica. Silva ha escogido las cosas más efímeras y fugaces - "lirio que te deshojas", "rayo de luna", "verdes hojas / Que al tibio soplo de Mayo abrís" - y las ha adornado con adjetivos del mismo carácter- "frágil", "pálido", "húmedo", „tibio,.. En poemas como éste, Silva es el pintor impresionista que quiere coger la calidad luminosa y momentánca de las cosas-luminosa en sus breves momentos de vida y momentánea en su disolución inminente. El sentido doloroso de las palabras iniciales - " Si os encerrara yo..."- se intensifica en la segunda estrofa del poema, en que reaparecen las sombras y donde las frágiles cosas se convierten en fantasmas grises: 
¡Si aprisionaros pudiera el verso

Fantasmas grises, cuando pasáis,

Móviles formas del Universo,

Sueños confusos, seres que os vais,

Ósculo triste, suave y perverso

Que entre las sombras al alma dais,

¡Si aprisionaros pudiera el verso

Fantasmas grises cuando pasáis!

Aquí podemos ver claramente el anhelo frustrado de Silva, de coger y fijar las cosas. A pesar suyo, la luz se convierte en sombra y las cosas en fantasmas.

Hay sólo un poema, que sepamos, en que la luz se mantiene hasta el fin, sin la intervención fatal de la sombra, y donde se ve muy claramente el sentido de Silva ante la fugacidad de las cosas:

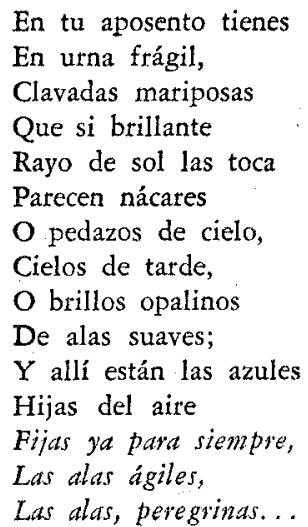

("Mariposas", pág. 79).

Estos últimos versos son de suma importancia. Lo que llama la atención del poeta es el hecho de que las mariposas - tal vez la cosa más móvil y efímera que se puede imaginar- están "fijas" para siempre. Estas "azules/ Hijas del aire", luminosas y vivas, nunca volverán a la sombra, nunca morirán. Êsta es la vida ideal, la vida que es vida y nada más que vida, el escape de la condición mortal.

Hay que notar además que el recurso expresivo más destacado ha dejado de ser el verbo, y es, al contrario, el sustantivo y el adjetivo. El poeta se esfuerza por nombrar las cosas de mayor blancura y diafanidad; "lirio", "flor", "rayo", "nácares", "brillos"; y adorna estas cosas con adjetivos luminosos e impresionisțas: "frágil", "pálido", "húmedo", "ti- 
bio", "brillante", "azules". Esta es una poesía sumamente sùstantiva, una poesía bañada en la luz trémula del sol, una poesía impresionista que quiere coger las cosas en su luminosidad momentánea. Es el complemento directo de la poesía tenebrosa que acabamos de ver, pero rarísima y escasísima entre los poemas de Silva. Lo que prevalece y domina es la sombra y el claroscuro del crepúsculo, porque el poeta no puede escaparse de la idea de la muerte y de la disolución de todo lo vital que él quiere tanto. La obsesión de la muerte en Silva no es más que el ansia de vivir, de sobrevivir, y la confrontación dolorosa con la mortalidad produce en él una angustia terrible. "Toda la angustia de Silva radica... en una ansia de vivir. .."7

Hemos visto al poeta ante un mundo donde la muerte se identifica con la vida misma y donde todo parece encaminarse hacia la disolución y el no-ser. Silva ve en el mundo en torno el reflejo de sus propios procesos interiores, y la historia de las cosas se hace la historia de su alma. Mas a diferencia de aquéllas, inanimadas e inconscientes, el poeta se da cuenta de su condición mortal. "Sufre este mal: . . pensar... ésa es la causa/ De su grave y sutil melancolía..." ("Psicopatía", pág. 102). Así describe Silva al poeta melancólico. Lo que Amado Alonso ha dicho de Neruda de Residencia en la tierra, del Neruda poeta de la disolución, puede decirse justamente de Silva, su precursor en muchos sentidos: "El morir de las cosas se identifica con nuestro morir. Y el poeta se angustia." 8

El poeta se angustia y busca apoyos: busca la duración y la claridad, y espera crearlas en la poesía. El arte será para él lo que ha sido para muchos otros, un medio de salvarse, o, por lo menos, una esperanza de salud, en medio de los hechos dolorosos de la vida. ". . esta región oscura, donde hoy me muevo sin ver más en el horizonte que el abismo negro de la desesperación, y en la altura; allá arriba, en la altura inaccesible, su imagen, de la cual, como de una estrella en noche de tempestad, cae un rayo, un solo rayo de luz!'s Así habló Silva de la poesía en su única novela que es una especie de journal intime donde vertió todos sus anhelos, todas sus esperanzas y angustias. $Y$ dirigiéndose a una amiga en una carta que sirve de prefacio a otra pieza de prosa, le dijo: "Es que Ud. y yo somos más felices que los otros... porque hemos escogido un mundo donde no hay desilusiones ni existe el tiempo"..10 Aquí tenemos la aspiración fundamental de Silva y su ars poetica: poesía es una bús-

7 Roggiano, Op. cit., pág. 607.

8 Op. cit., pág. 24.

9 Pasaje citado por el señor Torres-Ríoseco, Precursores del modernismo. (Madrid, 1925), pág. 121.

10 Prosas, (Bogotá, 1926), pág. 16. 
queda de la luz y de la duración, una búsqueda de un escape de la condición mortal. "!Si os encerrara yo en mis estrofas/ Frágiles cosas que sonreís... Si aprisionaros pudiera el verso...".

Pero como veremos en seguida, la poesía, siendo una creación humana, tal vez la más humana de todas (con las demás artes), comparte con el hombre su condición de hombre, su mortalidad.

\author{
Soñaba entonces en forjar un poema, \\ De arte nervioso y nuevo, obra audaz y suprema... \\ Llamé a todos los ritmos con un conjuro mágico \\ $\mathrm{Y}$ los ritmos indóciles vinieron acercándose, \\ Juntándose en las sombras, huyéndose y buscándose...
}

("Un poema", pág. 86)

Las materias de la poesía parecen tener la misma fluidez y movilidad que tienen los sueños de medianoche y los pálidos lirios que se deshojan, Aqui tenemos los mismos elementos estilisticos que ya hemos visto en la poesía de Silva: el gerundio y el símbolo de la sombra. La poesía de Silva, a pesar suyo, se hace un monumento al tiempo y a la muerte. Va creando una poesía que en todas sus formas, en todos sus simbolos, participa en el dinamismo del cosmos. El gerundio y el imperfecto quedan como las formas predilectas de Silva; la sombra y la muerte siguen siendo el fondo y la acción de su poesía.

Es menester ahora, después de haber considerado algunos elementos esenciales del estilo de Silva, detenernos a examinar su poema más famoso, el célebre "Nocturno", de todos conocido y que ha llamado la atención y la admiración de cuantos lo hayan leído - la expresión más perfecta del arte de Silva y el más completo testimonio de lo que vamos diciendo.

El tercer "Nocturno" es, sin duda, la suma del arte silviano, en su contenido y en su forma.

Los elementos importantes de este poema son la sombra, la luna, y las figuras de los amantes que parecen hacerse parte de la escena. Nunca los vemos, nunca los ve el poeta, menos en sombra, menos como sombras. Son parte de la noche, parte de la negrura infinita que los rodea, y la luna proyecta sus figuras sobre la arena, sus sombras figuradas. Participan en la luz y en la oscuridad a la vez, como si hubiera una línea que iba desde la luna hasta el suelo, pasando por los amantes y juntándolos al cielo y a la tierra. En sus sombras proyectadas sobre la arena, su "sola sombra larga", hay reunidas todas las presencias del universo - la luz, la oscuridad, $y$, en medio, el hombre. Mas esa sombra doble que se hace una se está deshaciendo desde el momento de su formación, puesto que 
debe su existencia a la luna que pronto desaparecerá: la fuerza repetitativa de " $i Y$ era una sola sombra larga!" es una fuerza disminuyente. La unión de los amantes en la sola sombra larga que se proyecta sobre las arenas, el estado ideal del cumplimiento de su amor, es transitoria y fugaz; su sombra está en proceso de deshacerse desde el momento de su formación, su muerte es implícita en su vida, y con la mengua de la luz de la luna, se disolverá, y retornará a la sombra y a la oscuridad de donde habia emergido unos momentos antes.

Nótese que aquí no hay gerundios; al contrario, el poeta no quiere que el poema se adelante; sobre todo, no quiere que el poema termine. Quiere prolongar este momento todo lo posible, hacerlo eterno, y todos los recursos estilísticos están empleados de acuerdo con este propósito: la frase, sobre todo la primera, se alarga, se dilata, para incluir al máximo número de elementos; hay pocos verbos y una superabundancia de sustantivos y adjetivos; y se repiten tres veces las últimas palabras de la primera estrofa, como si el poeta hiciese todo lo posible para prolongar este momento de éxtasis. Mas, a pesar suyo, el poema se mueve hacia el fin; los verbos, casi todos imperfectos, parecen arrastrar el poema a través de la página hacia el margen. La última esperanza del poeta es que los amantes van a encontrarse en otro mundo, donde este momento ideal y cumplido nunca acabará.

La mengua de la luz de la luna y la disolución de la "sola sombra larga" en la primera estrofa, se hacen los símbolos de la muerte de la amada en la segunda, y su separación del amado "por la sombra, por el tiempo y la distancia,/ Por el infinito negro,/ Donde nuestra voz no alcanza....; la sombra, el tiempo, la distancia, la negrura, se identifican con la muerte y se hacen símbolos de ella. Viendo las figuras de los amantes en sombra, como sombras, es como si el poeta las viese, como si los lectores las viésemos, como espectros del otro mundo, ya muertos aún en esta vida. Ya sombras, parecen presagiar la muerte, como cada cosa, cada hombre, presagia la muerte en su estado de evolución, de movimiento, hacia el no-ser.

Este tercer "Nocturno" es la expresión más perfecta de la analogía que existe entre los procesos de las cosas y los procesos del alma del poeta. El dinamismo del cosmos se hace el dinamismo de sus sentimientos, y las cosas en su movimiento eterno hacia el no-ser y la sombra se hacen sím. bolos del estado de ánimo del poeta en su calidad efímera y fugaz. "... dans l'expétience la plus intime, celle de la continuité personelle, se découvte une analogie niattendue entre le temps humain et le temps cosmique Le temps humain er le temps cosmique sont deux continus... 
le temps et l'espace deviennent le lieu des pensẹes comme celui de corps. L'âme participe... à l'existence universelle."11 Lo que Georges Poulet ha dicho aquí a propósito del sentimiento del hombre del siglo XIX con respecto al mundo, puede aplicarse con exactitud a Silva.

De aquí la tendencia de Silva a crear una poesía vaga y de nuance; ("Con el recuerdo vago de las cosas..." ["Infancia", pág. 37], "A la orilla del lago/ En donde el agua.../ Forja un paisaje tenebroso y vago". ["Al pie de la estatua", pág. 50], "La luz vaga ... opaco el día/ La lloviz na cae y moja/ Por el aire tenebroso" [Día de difuntos", pág. roo], "... una noche toda llena de perfumes, de murmullos, y de música de alas..." [Tercer Nocturno", pág. 68], etc.); de aquí sus afinidades con las teorías estéticas de Poe y, sobre todo, con los de los simbolistas. ${ }^{12}$

En fin, la poesía de Silva es un monumento al dinamismo de los procesos cósmicos, a la evolución, al tiempo y a la muerte. Pero a diferencia de los románticos que también escribieron poesía sobre estos temas, pero que fijaron su atención en un pasado irreparable y lamentaron el intervalo infranqueable que les sepạtó de él, Silva no mira atrás hacia un pasado ya hecho y fijo; se da cuenta, más bien, de la calidad dinámica de ese pasado, (y del presente), de un tiempo que tiene una especie de duración dinámica. "Le temps du I $9^{\text {e }}$ siècle est un mouvemlent quu se saisit à partir de sa cause originelle: il est un devenir qui est toujours futur." 13 Coger esta calidad de movimiento, de proceso, y recrearla en la poesía - éste era el propósito de Silva, el que le llevó a la creación de sus mejores y más originales poemas, y esta conciencia suya de la contingencia provisional y dinámica del universo, de la realidad, le identifica con los pos-tománticos. Los versos de Mallarmé, hablando del humo de su cigarrillo, se aplican perfectamente a Silva:

Toute l'âme résumée

Quand lente nous l'expirons

Dans plusieurs ronds de fumée

Abolis en autre rond 14

11 Georges Poulet, Etudes sur le temps bumain, (Edinburgh, 1952), pág. 39.

12. A nuestro juicio, Silva se identifica mucho más con los simbolistas que

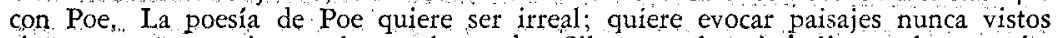
sino en sueños; quiere rechazar el mundo. Silva, con los simbolistas, al contrario, busca reflejos de su estado de ánimo en el mundo en torno. Sus técnicas se parecen, pero sus propósitos son diferentes.

13. Poulet, $O p$ cit., pág. 42.

14 Oeutrés complètes, (París: Edition de la Pléiade), pág. 73. 
La creación y la disolución, la vida y la muerte, se eslabonan en un solo proceso flúido mediante la dimensión del tiempo.

Nos parece indudable, después de este pequeño estudio de la poesía silviana, que Silva es un pos-romántico, propiamente dicho, que posee, claro está, un fondo romántico como todos los simbolistas. El simbolismo no es más que un refinamiento y un desarrollo del romanticismo en algunos de sus aspectos. "... romanticism does not die out in $185^{\circ}$ but branches out under different names like a delta." 15 "Silva posee un fondo romántico, pero de un romanticismo razonado y consciente, distinto, por lo tanto, del romanticismo europeo de 1830 . Sobre este fondo romántico se eleva su cinceladura parnasiana de la forma y el toque de asomo metafísico que el simbolismo ha prestado a todos los modernistas." 16 Añadiríamos sólo que en su esfuerzo por asir la realidad en su calidad dinámica, y de evocar un estado de ánimo fugaz mediante la evocación de esta realidad, con un estilo móvil y flúido, en una poesía sumamente impresionista y dinámica, Silva se identifica con los pos-románticos europeos, y ocupa un puesto importante en el desarrollo del pos-romanticismo hispánico del modernismo.

\author{
R. J. SCHWARTZ \\ Universidad de California, \\ Berkeley.
}

15 Jacques Barzun, Romanticism and the Modern Ego, (Boston, 1944), págs. 138-139.

16 Roggiano, Op cit., pág. 610. 
